\title{
Validación de un modelo de predicción del crecimiento urbano en Quito (Ecuador) construido mediante pesos de evidencia y autómatas celulares
}

René Ulloa-Espindola. Universitat Rovira i Virgili, Tarragona, España. Yolanda Pérez-Albert. Universitat Rovira i Virgili, Tarragona, España.

RESUMEN | Este artículo analiza el grado de predicción alcanzado por un modelo espacial de crecimiento urbano elaborado con base en (1) el comportamiento histórico de los asentamientos formales e informales en las periferias y en (2) las variables predictoras del fenómeno utilizando técnicas geoespaciales. Se toma como estudio de caso la periferia nororiental de la ciudad de Quito (Ecuador), espacio que ha sufrido una gran transformación en los últimos años. En un primer momento se construye el modelo espacial a partir de imágenes satelitales, complementadas con análisis de variables predictoras del fenómeno mediante la metodología de pesos de evidencia y autómatas celulares. Posteriormente, el análisis se centra en la validación del modelo a través de ventanas de tamaños múltiples con función de decaimiento constante para el análisis de patrones espaciales con DinamicaEgo ${ }^{\oplus}$. Como resultado, las proyecciones generadas del modelo muestran coincidencias consistentes con la realidad y un alto porcentaje de validación.

PALABRAS CLAVE | expansión urbana, tecnologías de información y comunicación, planificación urbana.

ABSTRACT | This article analyzes the degree of prediction achieved by an urban growth spatial model based on (1) the historical behavior of formal and informal settlements in the peripheries and (2) the predictive variables of the phenomenon using geospatial techniques. The case study is the north-eastern periphery of the city of Quito (Ecuador), a space that has undergone a great transformation in recent years, is taken as a case study. At first, the spatial model is constructed from satellite images, complemented by analysis of predictive variables of the phenomenon under weights of evidence and cellular automata. Subsequently, the analysis focuses on the validation of the model, through multi-size windows with constant decay function for spatial pattern analysis with DinamicaEgo ${ }^{\circ}$. As a result, the projections generated from the model show co-occurrences consistent with reality and a high percentage of validation.

KEYWORDS | urban sprawl, information and communication technologies, urban planning. 


\section{Introducción y objetivos}

Según el Banco Interamericano de Desarrollo (BID, 2011), Latinoamérica y El Caribe son las regiones que han registrado la más rápida urbanización en el mundo, lo que compromete la sostenibilidad del desarrollo urbano al producir desequilibrios ambientales, económicos y sociales en las ciudades, los cuales generan barreras infranqueables para un desarrollo sostenible. Para resolver estos desequilibrios es fundamental entender cómo funcionan las ciudades y su entorno regional, así como la influencia que tiene el ordenamiento territorial de los espacios colindantes (CEPAL, 2002; ONU-HABITAT, 2018). Las ciudades latinoamericanas urbanizadas están funcionando en el presente con la inercia derivada desde sus orígenes (Cuervo González, 2003). Actualmente el reto es doble: por un lado, aparece la necesidad de replanificar o rediseńar, estudiando todas las posibles maneras de cambiar los entornos ya habitados y ocupados; y, por otro, se requiere planificar nuevos desarrollos urbanos que den compacidad y eficiencia a la ciudad a la vez que minimicen el impacto de los crecimientos informales.

Un fenómeno latente que se produce en la ciudad de Quito en Ecuador es la acelerada ocupación dispersa del territorio periurbano-rural a través de asentamientos residenciales informales (Scholz et al., 2015). Sin embargo, los gobiernos locales, los que mejor conocen las necesidades y las vulnerabilidades de la población debido a su proximidad a ella, se inhiben y desatienden las demandas y aspiraciones de la ciudadanía; la gestión gubernamental se presenta débil en la planificación y mitigación de los impactos del desmedido crecimiento urbano de la ciudad.

Este crecimiento disperso de la ciudad de Quito ha provocado que la mancha urbana evolucione a un ritmo más acelerado que el crecimiento de la población (Martínez Beltrán, 2019), provocando que la concentración de equipamientos y empleos se ubique en lugares cada vez más alejados y dispersos y dificultando con ello el acceso de los habitantes al centro comercial y administrativo de la ciudad. Como consecuencia, la calidad de vida disminuye y la relación campo-ciudad se altera, lo que significa que el Gobierno Seccional debe destinar importantes presupuestos a provisión de infraestructura en zonas cada vez más alejadas y de baja densidad.

Una variable fundamental utilizada por las administraciones gubernamentales de Quito para predecir la necesidad de suelo urbanizable es la densidad media combinada con las tendencias de población y vivienda, respecto de las cuales Vaggione (2014) indica:Las necesidades de suelo dependen de las tendencias de densidad poblacional (...) dependiendo del crecimiento demográfico y de la densidad de población que se espera alcanzar, es posible calcular el suelo que se requiera para acomodar ese crecimiento. (...) y se calculan anticipadamente por períodos de 20 a 30 años. (p. 31)

La simple estimación de la necesidad de suelo carece de dimensión espacial, es decir, no indica en qué zona o zonas se ubicarán los nuevos asentamientos poblacionales. Para realizar una previsión que refleje la localización geográfica del fenómeno es 
necesario considerar la influencia de los factores y limitantes específicos de la ciudad como variables predictoras de la dinámica urbana.

Desde hace más de dos décadas, diversos trabajos de simulación y modelamiento urbano bajo ambientes geográficos han destacado por su funcionalidad; entre ellos, los de Tobler (1995), Couclelis (1997), Takeyama (1996) y White y Engelen (1997); otros más recientes son los de Feng, Liu y Batty (2016), Feng y Tong (2019) y Ma (2020). Teniendo en cuenta las características de la dinámica espacio-temporal en el mundo real, se requiere de una gran cantidad de variables y factores para modelar el territorio de forma realista (Ghosh et al., 2017). Aburas et al. (2016) realizan una revisión bibliográfica de experiencias de creación de modelos de crecimiento urbano a partir de autómatas celulares (AC) y establecen que los factores de accesibilidad, como la distancia a carreteras, autopistas y vías férreas, son los más importantes en los estudios urbanos, aunque no hay que dejar de lado los relacionados con las características físicas del territorio, básicamente la pendiente.

Los patrones actuales de crecimiento de las ciudades de la región sudamericana son extrapolables entre sí; por ejemplo, Quito, Lima y Bogotá presentan un comportamiento similar: la expansión de estas urbes se rige por factores y limitaciones específicas que atraen la proliferación de asentamientos formales e informales (Gómez Salazar \& Cuvi, 2016; Sabatini, 2003). Entre los más influyentes se encuentran, en primer lugar, la accesibilidad vial (oficial e informal), derivada de la partición de tierras suburbanas de grandes extensiones para formar parcelas que, en la mayoría de los casos, terminan destinadas a la urbanización y a la creación de manzanas no reguladas (Champion \& Hugo, 2017; Clichevsky, 2000). Este factor resulta ser el de mayor peso debido a que a través de él se dibujará la futura configuración urbana, pero, sobre todo, porque es la infraestructura a partir de la cual se instalan otros factores estimulantes, como los servicios básicos y complementarios (Rodríguez et al., 2016). Así, el tendido eléctrico, la infraestructura de agua potable y de saneamiento, la red de telefonía e internet y el servicio de transporte son factores asociados a las vías de comunicación que explican el crecimiento urbano. En segundo lugar, aparece la pendiente del terreno, considerando que las zonas con pendientes moderadas a altas, en lugar de ser un limitante, en realidad resultan ser atractivas para la ubicación de asentamientos (Gómez Salazar \& Cuvi, 2016). Por último, las edificaciones prexistentes (formales e informales) ejercen atracción para la instalación de nuevos asentamientos (García de Hernández, 2006).

Así, este trabajo tiene como objetivo diseñar una alternativa de monitoreo, medición y predicción del crecimiento expansivo de la mancha urbana de Quito. Para ello, se valora el grado predictivo que puede alcanzar un modelo geográfico basado en autómatas celulares de la expansión urbana en la periferia nororiental de la ciudad, sector Calderón (Figura 1). El modelo consta de dos entradas de información. Por un lado, las imágenes satelitales del crecimiento de la mancha urbana (asentamientos de infraestructura civil) desde el ańo 2003 hasta 2018. Por otro lado, el cómputo de las variables predictoras del crecimiento de la mancha urbana, bajo la metodología de pesos de evidencia. Los resultados son procesados mediante un modelo de autómatas celulares para calcular las proyecciones con base en mapas de probabilidades. Sin embargo, antes de producir las simulaciones 
futuras, el modelo debe ser evaluado para determinar el grado de predicción que puede alcanzar. En este sentido, el artículo presenta los valores de las similitudes espaciales resultantes de las comparaciones entre los escenarios generados por el modelo y el escenario real, evaluados en dos periodos, 2003-2014 y 2014-2018, y calculados bajo la metodología de similitudes recíprocas, analizadas con ventanas de tamaños múltiples con función de decaimiento constante.

\section{Área de estudio: parroquia de Calderón, Quito-Ecuador}

El Distrito Metropolitano de Quito (DMQ), uno de los principales nodos de centralidades en el Ecuador (Figura 1), se circunscribe dentro de la provincia de Pichincha y ocupa el 44,6\% de este territorio (Figura 1-C). Según el Instituto Ecuatoriano de Estadísticas y Censos (INEC, 2016), la tasa de crecimiento del área suburbana del DMQ es de 4,1\%, cifra que duplica la tasa de crecimiento de la ciudad (1,5\%). La parroquia de Calderón, ubicada en el extremo nororiental de la ciudad (Figura 1-D), se ha caracterizado por desarrollar un proceso de expansión urbana hacia los valles próximos y hacia la ciudad. Desde 1990 este sector ha experimentado una tasa promedio de crecimiento anual del 8\%, la cifra más alta registrada en el DMQ (Durán et al., 2016).

\section{FIGURA I | Situación geográfica del área de estudio}
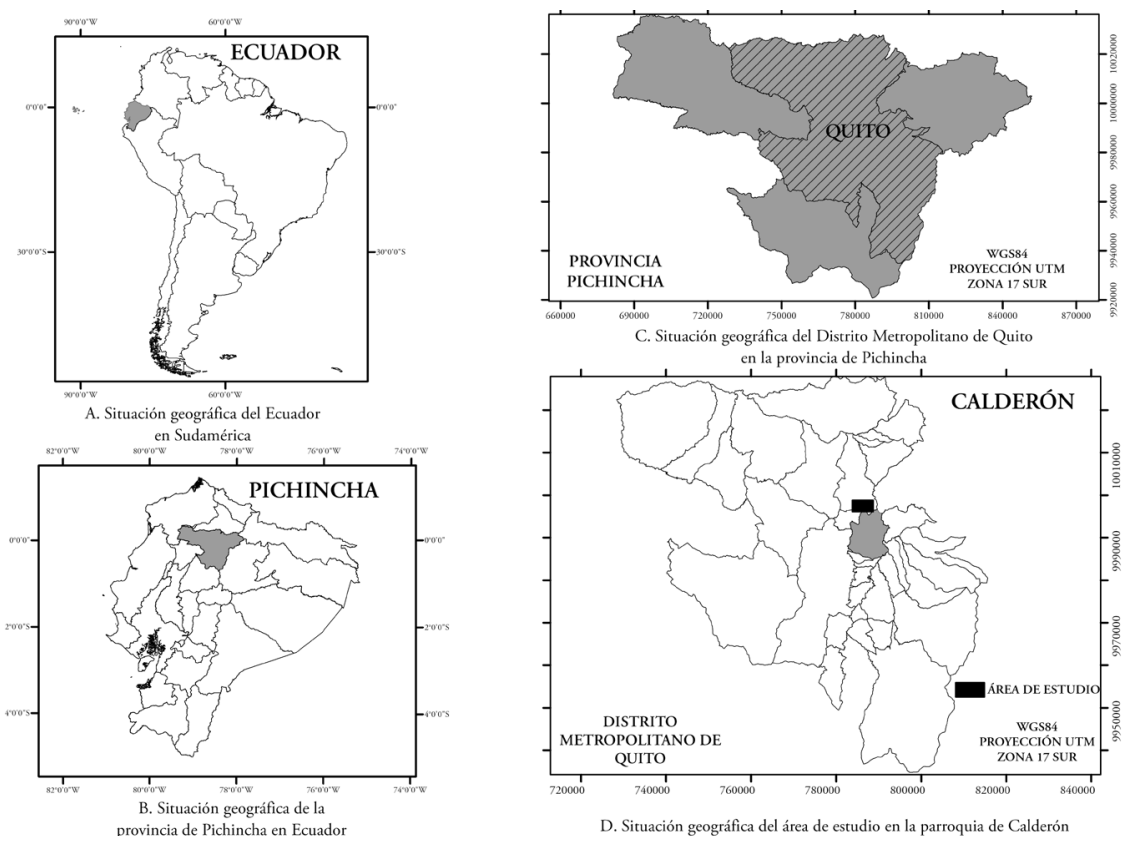

D. Situación geográfica del área de estudio en la parroquia de Calderón

FUENTE: ELABORACIÓN PROPIA A PARTIR DE INFORMACIÓN ESPACIAL DEL MUNICIPIO DEL DISTRITO METROPOLITANO DE QUITO (20I9) 
Los efectos del crecimiento disperso de las zonas periféricas de la parroquia se reflejan en la aparición de nuevos patrones de asentamientos urbanos formales e informales. Esta característica convierte la periferia norte de la parroquia (Figura 1-D) en una zona atractiva para estudiar la dinámica futura de expansión; tal es el motivo por el que ha sido seleccionada para desarrollar un modelo de simulación prospectivo de los asentamientos urbanos.

\section{Las ciudades como sistemas complejos}

Los estudios que abordan el análisis de la morfología de la ciudad han tratado de explicar, mediante la construcción de modelos, los patrones de los asentamientos urbanos con base en su propio pasado. Algunos trabajos clásicos, como los de Batty y Longley (1994), incorporan la geometría fractal para explicar el fenómeno. Por su parte, Cacciari (2010) valida la consideración de que la ciudad es un sistema vivo y enfatiza el símil entre ciudad, sistema natural y organismo. Bajo este mismo pensamiento, Oyugi y K'Akumu (2007) enfocan el estudio de los centros de la urbe desde una visión fisco-química, tratándolos netamente como seres vivos que se originan, crecen, se desarrollan y que, después de cierto tiempo, tienen la posibilidad de desaparecer (morir). Una de las definiciones relativamente recientes publicadas por Kennedy et al. (2007) sobre el metabolismo urbano enmarca la ciudad como una realidad compleja en todo su espectro, es decir, en todos sus elementos y en la suma de estos. Para Zhang et al. (2009), la ciudad es una especie híbrida entre sistemas ecológicos y sistemas económicos, donde coexisten los elementos naturales con los elementos sociales y económicos, los cuales interactúan bajo actividades rigurosas del desarrollo urbano y a la vez comprometen los ambientes circundantes. Maldonado (2014) define las ciudades según el mismo criterio de comparación con sistemas vivos, especificando que estas se arraigan bajo la apropiación del territorio y del espacio, así como con el flujo de intercambio de materia y energía, estableciendo jerarquías espaciales entrópicas con territorios cercanos. En definitiva, la ciudad se considera un ecosistema complejo en el cual interactúan agentes bióticos y abióticos con tendencia a crear sostenibilidad ambiental.

\section{Crecimiento urbano y sostenibilidad}

El proceso urbano de crecimiento y expansión conlleva cambios importantes en todas las dimensiones de la ciudad, principalmente en la morfología, debido a que las zonas periféricas se transforman en nuevas zonas centrales o pericentrales. Para Batty et al. (1999), el crecimiento urbano consiste en la interacción de tres dinámicas espaciales: (1) la centralidad del núcleo urbano, marcada generalmente por el origen que precede a la ciudad; (2) la presión de los bordes pericentrales que la ciudad ejerce en su desarrollo hacia el exterior; y (3) la rápida suburbanización en las periferias.

En el siglo Xxi, el desarrollo en tecnología y transporte modifica la intensidad de consumo y producción de las sociedades (Jackson, 1985). La pérdida del suelo que rodea a las ciudades -el cual se encuentra por lo general destinado a otras actividades, como la agricultura- es un proceso fragmentado y asistemático, que deja espacios ineficientes y poco aprovechables; como consecuencia, estas áreas de 
expansión tienen poca riqueza paisajística y pueden llegar a contaminar el atractivo visual del área urbana consolidada, situación que, según la superficie afectada, puede resultar un hecho irreversible (Torrens \& Alberti, 2000).

El fenómeno conocido como sprawl, desde un punto de vista netamente morfológico, se define básicamente por una dispersión urbana que es (1) de baja densidad, (2) de baja centralidad, (3) de baja proximidad, (4) de baja concentración y (5) con una presencia discontinua en el territorio (Muñiz et al., 2006). Este modelo de expansión presiona las periferias urbanas, aumenta el consumo de suelo y produce una alta fragmentación del territorio, con zonas residenciales aisladas y de baja concentración poblacional. Paralelamente afecta el ambiente destruyendo los recursos del entorno, lo que, a mediano y largo plazo, genera contaminación y perturbación ecológica.

Según algunos autores, como Batty et al. (1999) y Torrens y Alberti (2000), resulta muy complicado emitir soluciones prácticas para el mundo real con base en estudios del crecimiento urbano. No obstante, a nivel mundial se producen estimaciones urbanas comparables a partir de imágenes satelitales, luces nocturnas y otros métodos de tal envergadura (United Nations, 2019).

\section{Los autómatas celulares (AC) y el modelamiento urbano}

El método de los Ac fue concebido por el matemático británico Alan Turing en los ańos treinta y desde entonces su idea se ha propagado con innumerables aplicaciones en diferentes campos científicos. Para Sakoda (1971), los AC son concebidos como un conjunto algorítmico. Estos, los AC, intentan modelar matemáticamente patrones basados en un conjunto de reglas para un sistema dinámico; de este modo, las células consiguen evolucionar según una determinada expresión, la regla de transición (Gómez, 2011).

Un AC es un sistema dinámico en el que el espacio se divide en celdas regulares y el tiempo avanza en periodos discretos. Cada celda del sistema tiene uno de un número finito de estados, el cual se actualiza de acuerdo con reglas locales. Es decir, el estado de una celda en un momento determinado depende de su propio estado $y$, consecuentemente, evoluciona al aplicar una función de transición (regla de evolución) que determina el estado futuro y define la mecánica de iteración. Una explicación detallada sobre las reglas de transición puede encontrarse en Weisstein (2019). Los elementos de cada celda son simples, pero en conjunto representan patrones complejos al evolucionar a través del tiempo.

Entre las aplicaciones de los AC en estudios urbanos destacan dos. La primera corresponde a la herramienta Duem (Dynamic Urban Evolutionary Model), creada en The Bartlett Center for Advanced Spatial Analysis de UcL (University College London) por Michael Batty, Yichun Xie y Zhanli Sun. La segunda es el proyecto Moland (Monitoring Land Use Changes) de Europa, el cual utiliza indicadores para el análisis de las dinámicas urbanas y regionales y ha inspirado varios de los modelos desarrollados en otros estudios, como los de Barredo et al. (2003) y Aguilera Benavente et al. (2010). 


\section{Metodología y fuentes}

La metodología diseñada y aplicada consta de seis fases: selección de la información de entrada y años de referencia; determinación de las tasas de transición; calibración del modelo mediante la selección de los pesos de evidencia; correlación de variables e independencia espacial; generación de escenarios o simulación y, por último, la validación del sistema.

\section{Selección de la información de entrada}

Para la validación y construcción del modelo de simulación de crecimiento urbano se escogen dos periodos de análisis: el primero, de 2003 (situación inicial) hasta 2014 (situación final); y el segundo, de 2014 (situación inicial) hasta 2018 (situación final). A partir de esos años de referencia se construye un modelo de simulación para cada periodo y su validación consiste en simular desde la situación inicial (real) hasta la final (simulada), y comparar la situación final simulada con la situación final real mediante el método de similitud recíproca con ventanas de tamaño múltiple con función de decaimiento de DinamicaEgo ${ }^{\odot}$.

En la operación de las simulaciones se utilizan coberturas binarias de los asentamientos urbanos para cada año de los antes mencionados, generadas a partir de imágenes satelitales clasificadas y rasterizadas en dos usos: construcción (codificado con 1) y suelo sin construcción (codificado con 0 ). Tales coberturas se obtienen a partir de la interpretación visual de las imágenes satelitales de Google (cNes/AirBus) de los ańos correspondientes, identificando principalmente las construcciones civiles que han ocupado el suelo en los periodos establecidos. La resolución espacial de las imágenes satelitales a partir de las cuales se digitalizaron las coberturas es de 4 metros (tamaño del píxel) y su interpretación se realizó a escala 1:15.000, procurando identificar construcciones desde cuatro metros cuadrados de superficie, las conocidas "mediaguas" (construcciones temporales típicas de los asentamientos que suelen ser utilizadas para guardianía y bodegas de materiales). Cabe recalcar que se han asignado valores nulos a los ejes viales de la zona, ya que en estas áreas no deben posicionarse asentamientos.

Para complementar y calibrar el modelo se introduce información de los factores y limitantes como variables predictoras que resultan más relevantes en la zona de estudio, y que permiten ajustar el modelo con base en el comportamiento heredado y tradicional de ocupación del suelo del sector (Tabla 1), fundamentado en:

- Concentración de asentamientos alrededor de infraestructura considerada “imán” o atractor del fenómeno, como: redes viales oficiales e informales (calles artesanales, no oficiales, sin cobertura de rodaje y sin aceras) (1); redes de distribución de agua potable y saneamiento (2); tendido eléctrico de media y alta tensión (con la disponibilidad, o no, de acometidas domiciliarias) (3); proximidades de instituciones educativas (6) y de salud (7); asentamientos con construcciones preexistentes (píxeles de categoría 1) (8); y

- Asentamientos ubicados en función de la topografía y las condiciones del suelo: diferentes pendientes del terreno (4) y diferentes calificaciones del suelo (5). 
TABLA I | Variables predictoras escogidas para calibración del modelo

\begin{tabular}{|l|l|l|l|}
\hline \multicolumn{1}{|c|}{ VARIABLE } & ESCALA & \multicolumn{1}{|c|}{ INSTITUCIÓN } & FECHA \\
\hline 1. Distancia a red vial y calles & $1: 5.000$ & Municipio de Quito & 2016 \\
\hline 2. Distancia a redes de agua y saneamiento & $1: 10.000$ & Empresa de Agua Potable y Saneamiento & 2018 \\
\hline 3. Distancia a tendido eléctrico & $1: 5.000$ & Empresa Eléctrica de Quito & 2018 \\
\hline 4. Pendiente del terreno & $1: 1.000$ & Municipio de Quito & 2010 \\
\hline 5. Calificación de uso del suelo & $1: 5.000$ & Municipio de Quito & 2016 \\
\hline 6. Distancia a instituciones de educación & $1: 5.000$ & Municipio de Quito & 2014 \\
\hline 7. Distancia a instituciones de salud & $1: 5.000$ & Municipio de Quito & 2014 \\
\hline 8. Distancia a asentamiento existentes & $1: 15.000$ & Imágenes Google Earth & 2018 \\
\hline
\end{tabular}

Cabe recalcar que tanto las coberturas de asentamientos urbanos como las variables predictoras deben ser rasterizadas y procesadas para que en las operaciones posteriores sean compatibles entre sí. Por esta razón, en las variables 1, 2, 3, 6 y 7, se calcula la distancia euclidiana a partir de los elementos presentes en cada capa (ejes viales, redes de agua, instituciones de salud y educación, etcétera). De esta manera, todas las variables se rasterizan de tal forma que cuenten con valores en toda el área de estudio, lo que habilita calcular los pesos de evidencia (Figura 2-B). La variable 8 se genera dentro del modelo con base en las coberturas de asentamientos de cada periodo a través de Calc_Distance_Map de DinamicaEgo ${ }^{\oplus}$ (Figura 3-A-B).

En la Figura 2-A se muestran los asentamientos del área de estudio en los diferentes años de referencia. En 2003, el área total de asentamientos y construcciones consolidadas suma $1,14 \mathrm{~km}^{2}$; para 2014, el incremento de ocupación de construcciones civiles fue $116 \%\left(2,46 \mathrm{~km}^{2}\right)$; en los cuatro años posteriores (2018), el área alcanzó $3,25 \mathrm{~km}^{2}, 32 \%$ más que en 2014 . Como tendencia general se aprecia un eje de expansión lineal de los desarrollos urbanos, de sur a norte, rellenando los espacios de un crecimiento disperso inicial, mientras que la consolidación urbana se concentra al sur; por último, existen asentamientos en laderas con pendientes considerablemente altas. 
FIGURA 2 | A: Evolución de asentamientos en los diferentes periodos.

B: Factores y limitantes (variables predictoras procesadas)

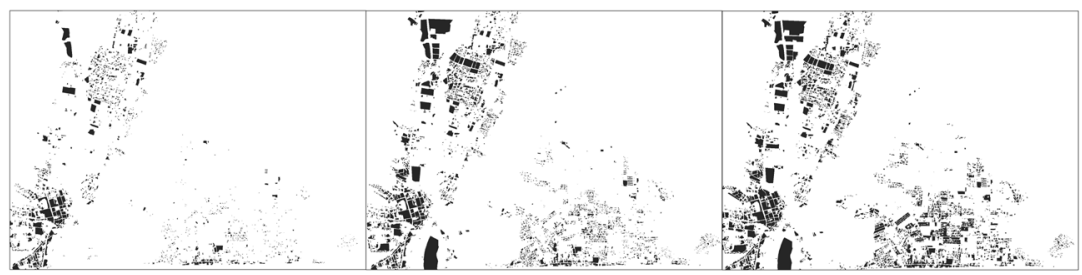

A1. Asentamientos 2003 A2. Asentamientos $2014 \quad$ A3. Asentamientos 2018
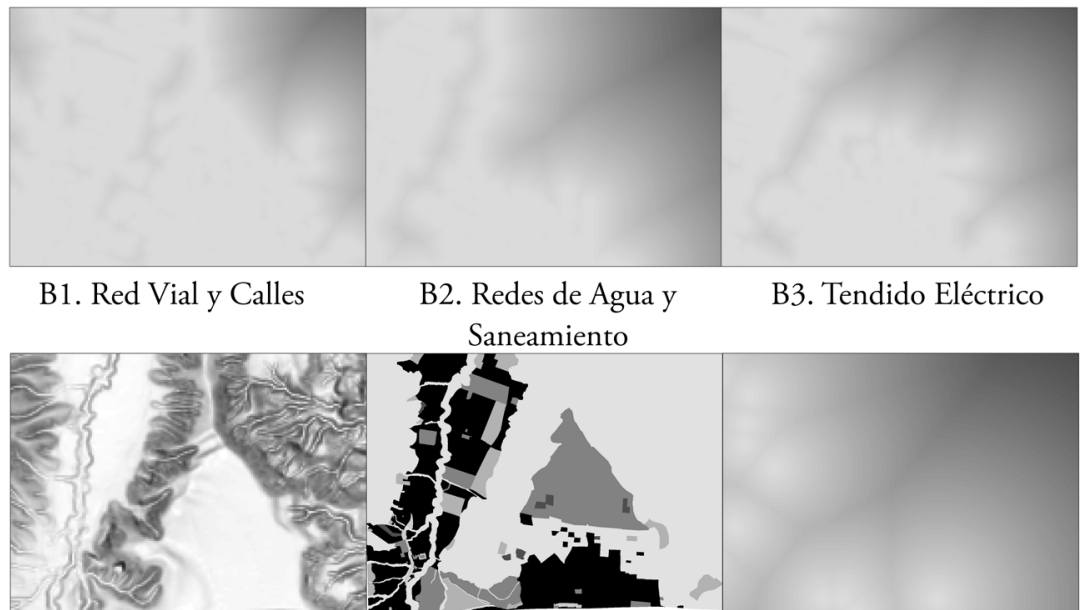

B4. Topografía/Pendientes

B5. Calificación de Uso

B6. Educación del Suelo

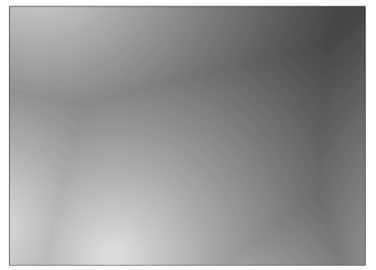

\section{LEYENDA}

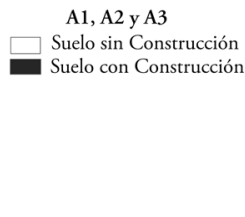

$\mathrm{B} 1, \mathrm{~B} 2, \mathrm{~B} 3, \mathrm{~B} 6$ y $\mathrm{B} 7$

B5

Mayor a 5.000 metros

Residencial

\begin{tabular}{cl|l} 
& & Residencial Rural \\
0 metros & Equipamiento \\
& Agrícola Residencial \\
B4 & Industrial \\
Mayor a 80 grados & Uso Múltiple \\
& $\square$ Protección Ecológica \\
\hline
\end{tabular}

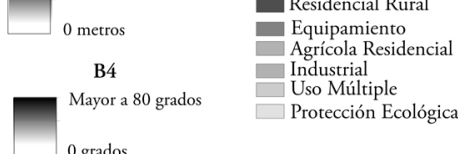

B7. Salud

FUENTE: ELABORACión PROPIA A PARTIR DE GOOGLE (CNES/AIRBUS)

\section{Transiciones}

Las tasas de transición reflejan las cantidades netas de cambio comprendidas entre periodos; esto significa que se calcula el porcentaje de área que ha cambiado de estado entre los años de referencia (función Determine_Transition_Matrix de DinamicaEgo ${ }^{\odot}$ ). Así, se asignará valor 1 cuando el cambio de uso, la transición, haya sido de suelo sin construcción (0) a suelo con construcción (1). Este cálculo se realiza a través de matrices de transición históricas (matrices de transición de 
asentamientos) que corresponden a las cadenas de Markov. Para Mondal et al. (2017) y Ghosh et al. (2017), las cadenas de Markov combinadas con los AC son un instrumento poderoso para estudiar los cambios espaciales multitemporales del uso del suelo y se utilizan ampliamente en modelamientos de crecimiento urbano. Este procedimiento se basa en representar los cambios producidos en periodos discretos de tiempo, resultando que el valor de la variable estudiada (área de asentamientos) en un tiempo específico es la suma de los valores previos de la variable. En definitiva, el cálculo de una tasa bruta fija por unidad de tiempo puede realizarse al dividir el cambio acumulado a lo largo del periodo total por el número de intervalos de que se compone el periodo (Lambin, 1994).

\section{Pesos de evidencia}

Uno de los objetivos en la construcción del modelo es determinar las variables que mejor expliquen el fenómeno, dado que la mejor o peor elección de ellas determinará el grado de precisión en la predicción del último. Para este propósito se usa la metodología de "pesos de evidencia", basada en las probabilidades condicionales de T. Bayes (bayesianas) (función Determine_Weigths_of_Evidence de DinamicaEgo ${ }^{\odot}$ ), con el fin de generar un mapa de probabilidades de transición que refleje las áreas donde el cambio tiene más posibilidades de ocurrir (Goodacre et al., 1993). La estadística bayesiana, frente a una aproximación frecuentista, utiliza la probabilidad para cuantificar la incertidumbre; es decir, basa las conclusiones sobre un fenómeno en el conocimiento previo del sistema y en las nuevas evidencias observadas; por lo tanto, este enfoque reasigna la credibilidad a través de las probabilidades de ocurrencia del mencionado fenómeno (Ruiz-Benito et al., 2018). Entre las ventajas de la estadística bayesiana se puede destacar: (1) la interpretación de los resultados es directa debido a que el método bayesiano es inductivo y merma la arbitrariedad de los límites para tomar decisiones; además, las estimaciones son más precisas, ya que se considera a los más probables; y (2) permite retroalimentar el estudio con información previa al mismo, ya que asume que la evidencia apoya o descarta la hipótesis (Rendón-Macías et al., 2018).

Este método geoestadístico se basa en el efecto que ejerce una variable espacial (variable independientepredictora) sobre la transición de otra variable espacial (variable dependiente), calculada independientemente; es decir, que los pesos de evidencia reflejan la influencia que ejercen las diferentes variables en la probabilidad de la ocurrencia de una transición (Soares-Filho et al., 2013). Como este procedimiento se basa en el método bayesiano, se calcula a través de probabilidades condicionales de la siguiente forma (ecuaciones 1 y 2 ):

$$
\begin{gathered}
O\{A \mid B\}=\frac{P\{A \mid B\}}{P\{\bar{A} \mid B\}} \\
\log \{A \mid B\}=\log \{A\}+W^{+}
\end{gathered}
$$

donde A representa el evento o fenómeno (asentamientos con construcciones) influenciado por un factor o predictor B y W es el peso de evidencia de ocurrencia 
del evento A. Para un conjunto de factores o predictores se expresa de la siguiente forma (ecuación 3):

$$
P\{\text { cambio } \mid M \cap V \cap S \ldots N\}=\frac{e^{\sum w_{N}}}{1+e^{\Sigma w_{N}}}
$$

donde $\mathrm{M}, \mathrm{V}, \mathrm{S} \ldots \mathrm{N}$, son las variables predictoras representadas por sus pesos de evidencia $\mathrm{W}_{\mathrm{N}}$.

Dado que este método solo trabaja con variables categóricas, es obligatorio categorizar las variables continuas consideradas en este estudio (mapas de distancia, pendientes, datos cuantitativos, etcétera); para este cometido, se aplica una adaptación del método de Goodacre et al. (1993) a fin de calcular rangos con base en la estructura de los datos y con la configuración de incrementos e intervalos (buffers incrementales). De esta manera se calculan rangos para categorizar variables continuas. Cada uno de los rangos divide la cobertura de la variable analizada en dos clases: el área (número de celdas) que se encuentra dentro del rango (buffer) y el resto del mapa. Los pesos de evidencia se calculan para cada rango en secuencia ordenada, tomando en cuenta el número total de celdas incluidas en el rango versus el número de celdas del evento (A) dentro de ese rango (función Determine_Weigths_of_Evidence_Ranges de DinamicaEgo ${ }^{\oplus}$ ). En este sentido, la única variable que es categórica y se excluye de este proceso es 'calificación de uso del suelo' (5), Tabla 1.

\section{Correlación de variables - independencia espacial}

Una de las pocas desventajas del método de pesos de evidencia es que asume que las variables espaciales son condicionalmente independientes entre sí; por lo tanto, cada variable deberá ser evaluada contra las demás para determinar el supuesto de independencia espacial (función Determine Weigths_of_Evidence_Correlation de DinamicaEgo ${ }^{\oplus}$, véase Figura $\left.3-A\right)$. Algunas pruebas estadísticas, tales como el test de Cramer y el test de incertidumbre, se ejecutan para cada combinación pareada de las variables explicativas del fenómeno (Bonham-Carter, 1994).

Bonham-Carter (1994) considera que si los resultados de las pruebas sobrepasan el valor de 0,5 , significa que existe alta correlación entre ese par de variables; por lo tanto, una de ellas deberá ser eliminada o podrá ser combinada.

\section{Generación de escenarios (simulación)}

Para obtener las coberturas simuladas (escenarios) en cada uno de los periodos planteados, 2003-2014 y 2014-2018, el modelo basado en autómatas celulares requiere como principal insumo un mapa de probabilidades, el cual se genera a partir de los pesos de evidencia y las tasas de las matrices de transición. Esta cobertura muestra, para cada celda, el grado de probabilidad de ocurrencia del evento estudiado; en este caso, las áreas más propensas a ser ocupadas por viviendas y/o asentamientos informales. A partir de este insumo de probabilidades se derivan las reglas que guían la dinámica de los autómatas celulares para generar los escenarios proyectados de las 
posteriores generaciones (Figura 3-B, función Calc W._o_E._Probability_Map_y_ Patcher de DinamicaEgo ${ }^{\oplus}$ ) (Rodrigues et al., 2007).

Para el periodo 2003-2014, las iteraciones del modelo son 11; es decir, para cada año proyectado se genera un mapa de probabilidades basado en la última generación, comenzando desde 2003, lo que significa que se producirán 11 mapas de probabilidades. Para el periodo 2014-2018 se generarán 4 iteraciones, por lo tanto, 4 mapas de probabilidades. En consecuencia, para cada periodo se producen 11 y 4 proyecciones simuladas, respectivamente. La última generación proyectada de cada periodo (2014 proyectada y 2018 proyectada) es la que se utilizará para la validación del grado de predicción, al ser comparada con las coberturas reales correspondientes al mismo año, 2014 y 2018 (Ulloa \& Lalama, 2018).

\section{Validación de la simulación}

El objetivo principal de este artículo es verificar el grado de predicción que alcanzan las simulaciones generadas por el modelo espacial construido. Con esta finalidad se ocupa una validación basada en una función exponencial de decaimiento constante, aplicada en ventanas de tamaños múltiples, la cual trabaja bajo un contexto de vecindad, debido a que es muy difícil que los mapas evaluados (simulado vs. real) concuerden exactamente celda a celda. Sin embargo, pueden presentar patrones espaciales parecidos y similitud espacial dentro de cierta vecindad de celdas o píxeles. Hagen-Zanker (2009) desarrolló nuevas técnicas de comparación espacial que incluyen la Kfuzzy, que equivale a los conocidos estadísticos Kappa y a la similitud fuzzy y que han sido utilizados en el análisis de sensibilidad para validar modelos basados en autómatas celulares. Otro trabajo referencial es el de Barreira González et al. (2015).

DinamicaEgo ${ }^{\oplus}$ utiliza una modificación de los estadísticos antes mencionados a través de la función Calc_Reciprocal_Similarity (Figura 3-C), que aplica una función exponencial de decaimiento, determinando la distribución del peso de las celdas de una ventana específica (kernel) en función de la celda central. La función exponencial de decaimiento que calcula la probabilidad de similitud se expresa de la siguiente forma (ecuación 4):

$$
S=\frac{1}{2^{\left(\frac{d}{A}\right)}}
$$

donde d es la distancia desde el centro de la ventana y A es un factor de atenuación. Este parámetro de atenuación controlará la rapidez del decrecimiento de los valores de la función (ventana kernel 3x3 detalla los valores de probabilidad en función de la celda central, véase Figura 4-C). Tal y como se aprecia en la Figura 4 A B, el factor de atenuación 1 produce un decrecimiento mucho más rápido que el factor de atenuación 10 . 
FIGURA 3 | Submodelos DinamicaEgo ${ }^{\circledR}$, fases metodológicas

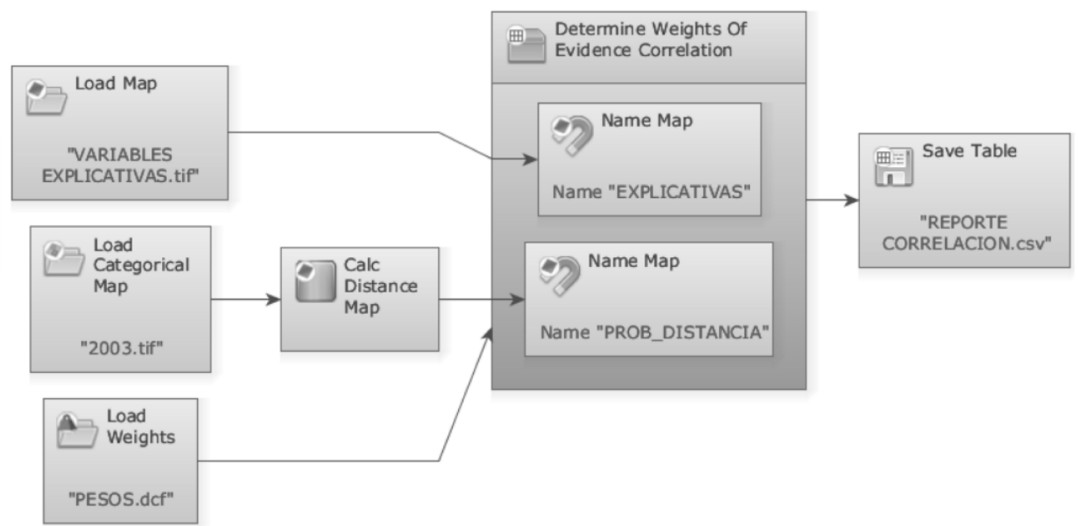

A. Modelo DinamicaEgo® que calcula la correlación entre variables predictoras

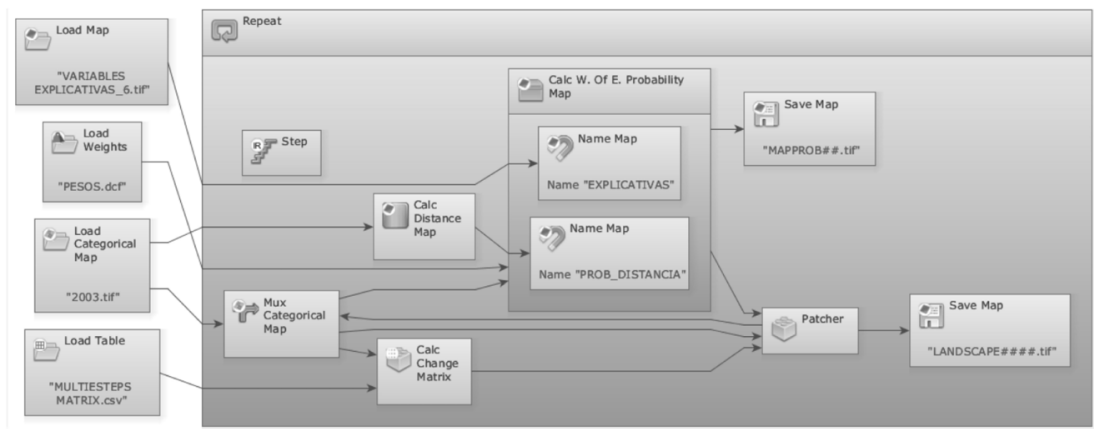

B. Modelo DinamicaEgo ${ }^{\circledR}$ que genera las simulaciones desde el inicio del periodo, "patcher" es la función de AC

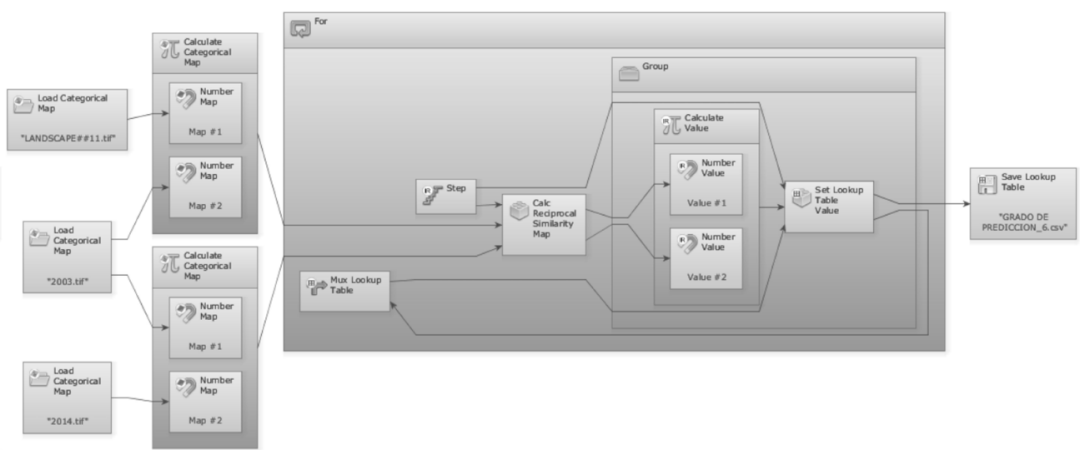

C. Modelo DinamicaEgo® que ejecuta la validación basado en los resultados de las simulaciones vs. las coberturas reales 
FIGURA 4 | Función de Decaimiento con factor de atenuación y Ventana 3x3 con valores de probabilidad

A.

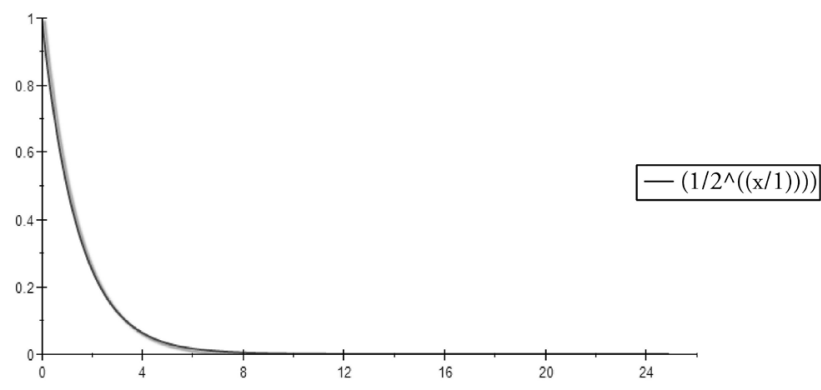

B.

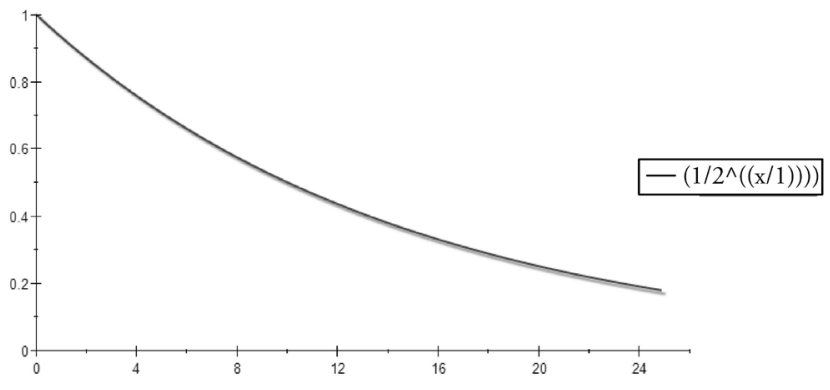

A. Función de Decaimiento con factor de atenuación igual a 1, $A=1$.

B. Función de Decaimiento con factor de atenuación igual a 10, $A=10$.

\begin{tabular}{|c|c|c|}
\hline 0,3 & 0,5 & 0,3 \\
\hline 0,5 & 1 & 0,5 \\
\hline 0,3 & 0,5 & 0,3 \\
\hline
\end{tabular}

C. Ventana $3 \times 3$ con valores de probabilidad, según la función de decaimiento

FUENTE: ELABORACIÓN PROPIA

En las condiciones en que este proyecto se ha desarrollado, el factor de atenuación (A) se determinó en 11, principalmente debido al tamaño del píxel (4 metros), al tamaño de la ventana de evaluación kernel de hasta $75 \times 75$ y a la consideración de que incluso a 300 metros de cada celda (celda central) existe posibilidad de que, por efecto de vecindad, se produzca un asentamiento.

Este procedimiento toma en cuenta una comparación en doble vía con los mapas de las diferencias, es decir, trabaja con la cobertura inicial $\left(\mathrm{CI}_{\mathrm{T}}\right)$, la cobertura final real $\left(\mathrm{CR}_{\mathrm{T}+1}\right)$ y la cobertura final simulada $\left(\mathrm{CS}_{\mathrm{T}+1}\right)$, para calcular dos mapas de diferencias. El primero corresponde a la diferencia que se establece entre la cobertura 
final real y el momento inicial $\left(\mathrm{D}_{1}=\mathrm{CR}_{\mathrm{T}+1}-\mathrm{CI}_{\mathrm{T}}\right)$; y el segundo, a la diferencia entre la cobertura final simulada y el momento inicial $\left(\mathrm{D}_{2}=\mathrm{CS}_{\mathrm{T}+1}-\mathrm{CI}_{\mathrm{T}}\right)$. A cada resultado $\left(\mathrm{D}_{1}\right.$ y $\left.\mathrm{D}_{2}\right)$ se le aplica una ventana kernel que recorre (convoluciona) toda la cobertura de los mapas de diferencias, aplicando la función de decaimiento constante a los valores de $\mathrm{D}_{1}$ con respecto a $\mathrm{D}_{2}$-y viceversa- para obtener el valor (fuzzy) de cada celda central.

\section{Análisis y resultados}

\section{La expansión urbana en el sector de Calderón (Quito, Ecuador)}

La expansión de los asentamientos en el área de estudio se encuentra próxima al límite administrativo norte del DMQ y se caracteriza por la informalidad de las construcciones y la acelerada expansión urbana. Además, colinda al oriente con el sector turístico Ciudad Mitad del Mundo, que está equipado con una infraestructura importante y robusta, por lo que se percibe como uno de los muchos factores que atraen asentamientos a la zona de estudio. Otra de las causas que puede generar cierta atracción de asentamientos es la construcción y ampliación de la autovía entre la zona de interés y Ciudad Mitad del Mundo, vía que conecta con el centro de la ciudad de Quito. La cantidad de construcciones civiles observadas en la zona, en lugares tanto consolidados como dispersos, ha aumentado significativamente en los periodos 2003-2014 y 2014-2018, a costa de usos de suelo como el agrícola o de equipamiento. Esta zona de 52 kilómetros cuadrados es de gran interés local, ya que la administración gubernamental planea la construcción de una planta de tratamiento de agua potable y tendido eléctrico de alta tensión, factores que se presume acelerarán los asentamientos informales.

\section{Tasas de transición}

Los valores de transición, es decir, la proporción de superficie que ha pasado de no construido (0) a construido (1), y viceversa, entre las coberturas binarias se calcularon para los periodos de 20032014 y 2014 2018. En los dos casos se obtuvieron valores totales que representan la tasa en todo el periodo y valores de las tasas para cada año. Considerando que en 2015 el crecimiento urbano espacial en la periferia de toda la parroquia alcanzó un incremento del 29\% con respecto a 2003, los valores presentados en la Tabla 2 y Tabla 3 ratifican la observación e interpretación de las imágenes satelitales. Asimismo, el área consolidada colindante al sur del área estudiada registró $7 \%$ de incremento en el mismo periodo; consecuentemente, en el periodo 2003 hasta 2014 la periferia estudiada presenta un aumento de 2,5\%, en el área de ocupación del suelo con asentamientos; sin embargo, en los cuatro ańos siguientes (2014-2018), registró un aumento del 1,6\%, pudiendo repetirse e incluso superar la tasa del periodo anterior en los próximos cinco años. 
TABLA 2 Matriz de transición multipasos, total del periodo

\begin{tabular}{|c|c|c|c|}
\hline \multirow{2}{*}{ PERIODO } & DESDE & A & TASA (\%) \\
\hline \multirow{2}{*}{$2003-2014$} & 0 & 1 & 0,236 \\
\cline { 2 - 4 } & 1 & 0 & 0,016 \\
\hline \multirow{2}{*}{$2014-2018$} & 0 & 1 & 0,538 \\
\cline { 2 - 4 } & 1 & 0 & - \\
\hline
\end{tabular}

FUENTE: ELABORACIÓN PROPIA

TABLA 3 | Matriz de transición anual

\begin{tabular}{|c|c|c|c|}
\hline \multirow{2}{*}{ PERIODO } & DESDE & A & TASA (\%) \\
\hline \multirow{2}{*}{$2003-2014$} & 0 & 1 & 2,561 \\
\cline { 2 - 4 } & 1 & 0 & 0,175 \\
\hline \multirow{2}{*}{$2014-2018$} & 0 & 1 & 1,607 \\
\cline { 2 - 4 } & 1 & 0 & - \\
\hline
\end{tabular}

FUENTE: ELABORACIÓN PROPIA

Test de independencia espacial de las variables predictoras

Tal y como se ha indicado en la metodología, se usan los valores de la prueba de Cramer y los valores de la prueba de incertidumbre de información conjunta para determinar la correlación espacial entre las variables predictoras. Los resultados de aplicar la prueba estadística que compara, de par en par, cada una de las variables contra todas las demás consideradas para la calibración del modelo, se pueden consultar en la Tabla 4.

Las correlaciones entre las variables 'red vial' y 'calles-redes de agua y saneamiento'; 'red vial' y 'calles-tendido eléctrico' y 'tendido eléctrico-distancia a asentamientos' generan valores de la prueba de Cramer de sobre los 0,5 puntos; por lo tanto, la correlación es significativa, de modo que los dos factores tienen el mismo comportamiento en cuanto a la variable independiente (los asentamientos urbanos). Además, la variable 'tendido eléctrico' aparece en dos de las correlaciones altas, resultado que se ratifica en la prueba de incertidumbre; por lo tanto, esta variable se ha excluido del análisis, debido principalmente a que los servicios de luz eléctrica, agua potable y saneamiento se encuentran instalados a través de la red vial y calles. Consecuentemente, se esperaba que estas tengan alta correlación. 
TABLA 4 Valores de las pruebas de Cramer e incertidumbre entre las variables

\begin{tabular}{|c|c|c|c|}
\hline VARIABLE I & VARIABLE 2 & CRAMER & INCERTIDUMBRE \\
\hline \multirow{7}{*}{ Instituciones de Educación } & Instituciones de Salud & 0,35286312 & 0,279213406 \\
\hline & Red vial y calles & 0,43188862 & 0,357569236 \\
\hline & Redes de agua y saneamiento & 0,41844450 & 0,387917926 \\
\hline & Uso del suelo & 0,26773566 & 0,208183045 \\
\hline & Tendido eléctrico & 0,42169710 & 0,393151269 \\
\hline & Topografía & 0,21112396 & 0,064793627 \\
\hline & Distancia a asentamientos & 0,44596339 & 0,453620854 \\
\hline \multirow{6}{*}{ Instituciones de Salud } & Red vial y calles & 0,33854588 & 0,229722229 \\
\hline & Redes de agua y saneamiento & 0,28194884 & 0,259984427 \\
\hline & Uso del suelo & 0,26054335 & 0,182046240 \\
\hline & Tendido eléctrico & 0,32945608 & 0,247877539 \\
\hline & Topografía & 0,19522409 & 0,049408826 \\
\hline & Distancia a asentamientos & 0,31761924 & 0,276313708 \\
\hline \multirow{5}{*}{ Red vial y calles } & Redes de agua y saneamiento & 0,53842650 & 0,433277223 \\
\hline & Uso del suelo & 0,27118806 & 0,213598850 \\
\hline & Tendido eléctrico & 0,60906490 & 0,570589919 \\
\hline & Topografía & 0,26418192 & 0,108575498 \\
\hline & Distancia a asentamientos & 0,47925819 & 0,441227101 \\
\hline \multirow{4}{*}{ Redes de agua y saneamiento } & Uso del suelo & 0,25975782 & 0,211571088 \\
\hline & Tendido eléctrico & 0,47210878 & 0,408047837 \\
\hline & Topografía & 0,26950053 & 0,097907201 \\
\hline & Distancia a asentamientos & 0,40965877 & 0,427356833 \\
\hline \multirow{3}{*}{ Uso del suelo } & Tendido eléctrico & 0,26887948 & 0,237345580 \\
\hline & Topografía & 0,30330919 & 0,192242246 \\
\hline & Distancia a asentamientos & 0,27275754 & 0,249417417 \\
\hline \multirow{2}{*}{ Tendido eléctrico } & Topografía & 0,28573373 & 0,124126716 \\
\hline & Distancia a asentamientos & 0,54159323 & 0,510613850 \\
\hline Topografía & Distancia a asentamientos & 0,26888199 & 0,112557390 \\
\hline
\end{tabular}

FUENTE: ELABORACIÓN PROPIA

\section{Generación de escenarios para validación}

Para ejecutar las validaciones correspondientes, es necesario contar con las coberturas reales y simuladas. Después de ejecutar el modelo, se han generado las reproducciones necesarias en cada periodo de análisis. En la Figura 5 se muestra la última generación de cada periodo y los mapas de probabilidades utilizados, coberturas que corresponden a las simulaciones de los años 2014 y 2018. 
FIGURA 5 | Simulaciones basadas en autómatas celulares

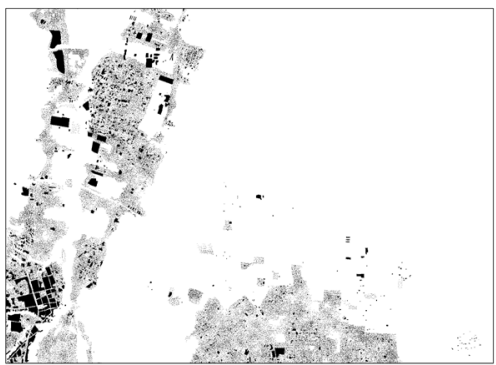

Cobertura simulada de asentamientos, año 2014

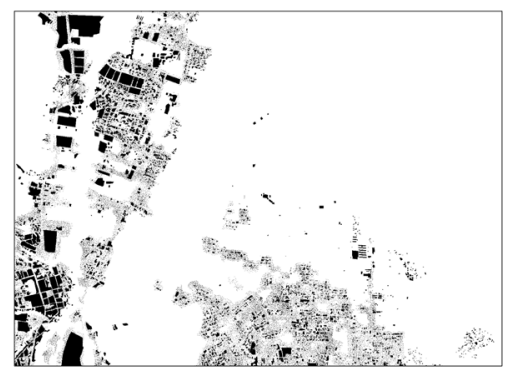

Cobertura simulada de asentamientos, año 2018

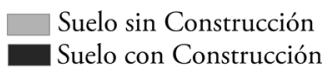

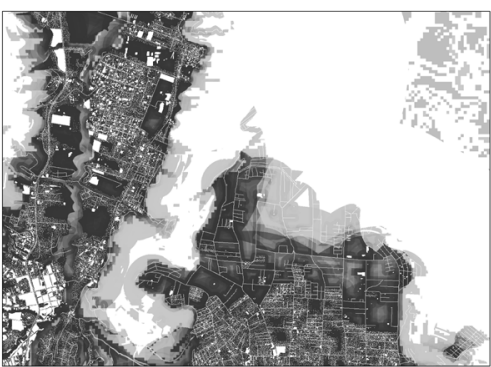

Mapa de Probabilidades de asentamientos, iteración 11, año 2014

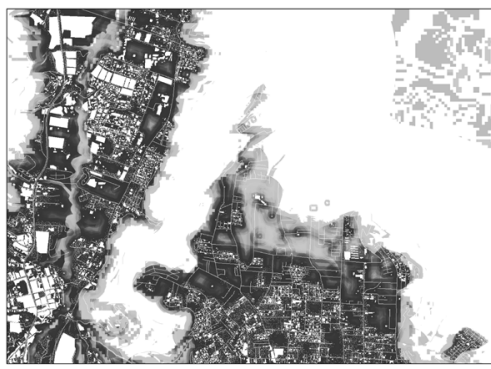

Mapa de Probabilidades de asentamientos, iteración 4, año 2018

Mayor a 90\% probabilidad de asentamiento
$0 \%$ probabilidad de asentamiento

FUENTE: ELABORACIÓN PROPIA

Los mapas de probabilidades muestran con colores oscuros las áreas con mayor probabilidad de ser ocupadas. Según observación en campo e interpretación, resulta muy acertada la proyección, ya que actualmente (2020) existen indicios de ocupación en la parte oriental de la zona de estudio, a pesar de que en el año 2018 (año de referencia del modelo), no existían asentamientos en esos lugares.

\section{Validación de la simulación}

Para el periodo 2003-2014 (Figura 6-A), la validación del modelo mediante la comparación de la cobertura real del año $2014($ CRT +1$)$ y su respectiva simulada 2014 $(\mathrm{CST}+1)$ utilizando el análisis de ventanas múltiples crecientes con una función de decaimiento, ha alcanzado una similitud del $71 \%$. Al aplicar el mismo procedimiento en el periodo de 2014-2018, la similitud alcanzada fue de 57\% (Figura 6-B). 
FIGURA 6 | Grado de predicción alcanzado

A.

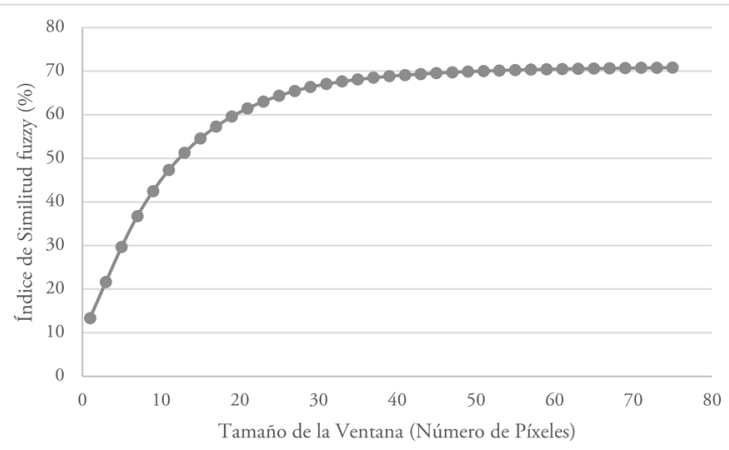

Índice de similitud basado en ventanas de tamaños múltiples para la simulación de la cobertura 2003-2014

B.

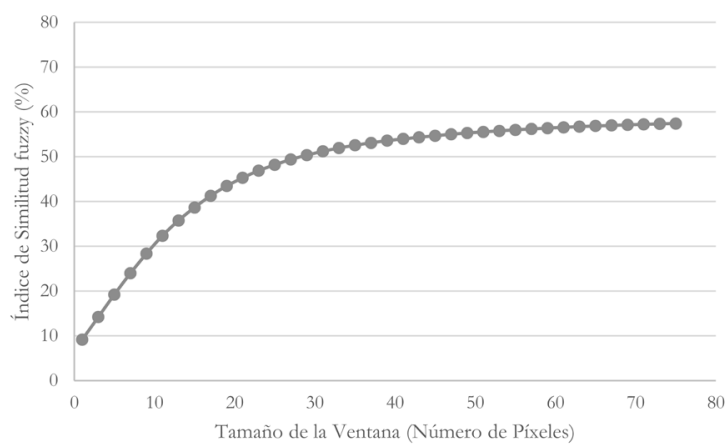

Índice de similitud basado en ventanas de tamańos múltiples para la simulación de la cobertura 2014-2018

FUENTE: ELABORACIÓN PROPIA

\section{Discusión y conclusiones}

Según Batty et al. (1999), los AC son los más utilizados entre los modelamientos urbanos para la simulación del crecimiento o expansión. Un procedimiento común entre los diferentes trabajos que abordan el tema es la construcción de los valores de transición con base en las variables predictoras (cálculo del mapa de probabilidades o potenciales de transición); entre los métodos más aplicados se encuentran la regresión logística y la evaluación multicriterio. Sin embargo, en estudios de modelamiento ambiental y cambio del uso del suelo es común encontrar el método "pesos de evidencia". White y Engelen (1993) calculan los potenciales de transición a través de un factor de aleatoriedad o factor estocástico; Batty y Xie (1996) consideran que este factor emula la aleatoriedad propia de los sistemas complejos (ciudades). En el trabajo de Valenzuela Montes et al. (2008) se calcula, con ciertas modificaciones, el potencial de transición inspirado en White y Engelen (1993). 
Linares y Picone (2018) crean un mapa de potencial de transición a través de una evaluación multicriterio, que implica la ponderación de cada variable predictora. Los trabajos de García Lamparte et al. (2013) y Aguilera (2006) ocupan la regresión logística para elaborar el modelo de predicción. El método de pesos de evidencia es utilizado por Mas y Flamenco (2011) y Sahagún-Sánchez et al. (2011) en modelos de cambio de uso de suelo; y en modelos de crecimiento urbano lo aplican Ulloa y Lalama (2018). Queda claro que la técnica para calcular los valores de transición influye directamente en la forma de proyectar el fenómeno, ya que es el insumo el que determina el comportamiento de los AC de generación en generación (iteración). Estas son las reglas del sistema. Por este motivo, en el caso de expansión urbana específica como las periferias de Quito, que muestran comportamientos y patrones de crecimiento tradicionales (locales), es más adecuado optar por técnicas que trabajen con evidencias y probabilidades (regresión logística, pesos de evidencia, evaluación multicriterio), que aquellas que introducen aleatoriedad en el proceso.

Respecto a la resolución de la información de partida (coberturas del crecimiento de la mancha urbana), la cual determinará la escala de las proyecciones generadas por el modelo, dicha resolución está condicionada por el nivel de identificación que se desea lograr y el método de digitalización que se aplique. Es decir, si la intención es representar el posible comportamiento de la mancha urbana a niveles de áreas metropolitanas, municipios o ciudades, la resolución de las celdas podría variar entre los 50 y 500 metros. Este es el caso de Aguilera Benavente et al. (2010), quienes, a pesar de disponer de fotografías aéreas a escala 1:10.000, presentan los resultados a nivel del área metropolitana de Granada (aprox. $800 \mathrm{~km} 2$ ); y en casos similares, Aguilera (2006) emplea un píxel de 50 metros de lado. También puede ser equiparable el estudio de White y Engelen (2000), quienes trabajan con un tamaño de celda de 500 metros de resolución en el ámbito de Holanda. En cambio, si se desea analizar dinámicas de crecimiento más aceleradas, dispersas y con mayor detalle (asentamientos-construcciones), la resolución espacial de las coberturas que representan los asentamientos deberá corresponder a las construcciones tipo que se reproducen en el área de interés. Es por tal razón que este trabajo identifica construcciones desde 4 metros cuadrados (resolución espacial de 4 metros). En consecuencia, las variables predictoras deberán disponer de la escala y precisión correspondientes para que el modelo provea de resultados adecuados.

Innumerables autores han utilizado el índice Kappa como indicador de la validez de los modelos de crecimiento urbano y cambio de uso del suelo. Barreira González et al. (2015), a pesar de las críticas a este índice, consideran necesario su uso y validan los diferentes escenarios generados por el modelo construido, obteniendo valores de similitud sobre el $70 \%$. Sin embargo, los autores indican que

(...) un punto importante de discusión sin resolver todavía por parte de la comunidad científica es si la comparación del mapa simulado con la realidad debe realizarse incluyendo la superficie urbana preexistente, además de la obtenida mediante la simulación o, por el contrario únicamente debe compararse el crecimiento simulado entre dos fechas con el crecimiento real. La mayor parte de los autores analizan los resultados incluyendo los píxeles ya existentes en el año de inicio de 
la simulación (es decir, se comparan los mapas simulados incluyendo la superficie prexistente), puesto que consideran que mantener los usos prexistentes es un acierto del modelo. De esta forma, al emplear cualquier tipo de procedimiento para comprobar la similitud entre simulaciones, los resultados indicarán que los mapas simulados son bastante parecidos a los reales, puesto que la superficie preexistente es bastante mayor que la ocupada por los crecimientos simulados. (Barreira González et al., 2012, p. 311)

Linares y Picone (2018) validan los resultados inspirándose en Pontius Jr. et al. (2008), con base en tres mapas: un mapa en tiempo 1, un mapa en tiempo 2, y un mapa simulado en tiempo 2, a través de tres medidas: figura de mérito, exactitud productor y exactitud usuario, obteniendo similitudes sobre el $80 \%$. En otro caso, Amuzurrutia-Valenzuela et al. (2015) validan un modelo de crecimiento urbano basado en una regresión logística, a través de un algoritmo de validación cruzada apoyado en muestras aleatorias. En los resultados de este trabajo se observan valores de validación entre $83 \%$ y $91 \%$ con una media de $86 \%$. La intención de este artículo es utilizar la metodología de validación que mejor se ajuste al fenómeno de crecimiento urbano acelerado y disperso. Si se considera que el efecto de atracción y repulsión de unos usos del suelo sobre otros decaen con la distancia (Tobler, 1970), resulta conveniente validar los resultados bajo este efecto (distance-decay effect), combinado con una evaluación recíproca para identificar patrones espaciales similares entre los mapas reales y los simulados. Soares-Filho et al. (2013) utilizan esta metodología en un modelo de cambio de uso de suelo con resultados de validación superior al $80 \%$. Cabe destacar que los resultados de validación obtenidos en este estudio se encuentran en $57 \%$ y $71 \%$ de validación, cifra que indica la bondad del modelo para predecir. Por lo tanto, la metodología de validación ha demostrado capacidad para comparar patrones de crecimiento y determinar similitud en situaciones de crecimiento acelerado disperso.

Entendiendo que los asentamientos en la zona han aparecido de forma dispersa, incluso a manzanas separadas y con deficiente consolidación, se ha determinado una ventana de evaluación de 75 píxeles (300 metros) y que el valor de atenuación de la función de decaimiento debe ser elevado; en este caso, mayor a 10, ya que esto mantiene la probabilidad de ocurrencia a distancias considerables.

Con respecto a las variables predictoras utilizadas para construir el modelo de la dinámica de ocupación del suelo a través de asentamientos con construcciones civiles, se puede concluir que las más importantes son 'distancia a red vial y calles' (formales e informales, que incluyen la apertura de carreteras y calles informales) y 'probabilidad por distancia a asentamiento' (creación de manzanas no reguladas). Por lo tanto, para este sector y para las periferias de Quito, estas variables son indispensables y quizá las más influyentes, debido a que los servicios básicos se instalan a su alrededor. Por consiguiente, variables como 'redes de agua y saneamiento' y 'tendido eléctrico' podrían tener alta correlación en el análisis pareado de variables, por lo cual deberán ser unificadas o, en su defecto, excluidas. Cabe recalcar que la variable generada a partir de las coberturas de crecimiento urbano alrededor de los 
asentamientos es indispensable para la calibración del modelo, pues brinda una probabilidad adicional.

Este trabajo demuestra que la combinación de las metodologías de pesos de evidencia y autómata celulares para modelar la expansión urbana acelerada y dispersa a partir de asentamientos formales e informales, aplicados a escalas de detalle, arroja resultados consistentes con la realidad con precisiones destacadas. El caso de estudio aplicado a la periferia urbana de Quito muestra que los escenarios proyectados explican de manera acertada el fenómeno de crecimiento urbano en la zona, ya que coinciden con los patrones de crecimiento de las coberturas reales, 2014 y 2018. La metodología diseńada es versátil y resulta más precisa que otros métodos, debido a que se basa en evidencias y comportamientos condicionados, brindando un efecto de naturalidad a los escenarios proyectados. Además, otros estudios confirman esta reflexión con nuevas aproximaciones, tal como lo hacen Feng y Tong (2019).

El uso del modelamiento urbano en general, y de esta metodología en particular, se percibe como imprescindible en el campo de la planificación urbana, puesto que permite, por un lado, vigilar la coacción entre los factores conductores de la expansión urbana y los patrones de crecimiento urbano; y, por otro, conocer con antelación cuál será la dirección del crecimiento de la ciudad. De este modo, los gestores de las administraciones públicas pueden actuar en consecuencia con el objetivo de contener la rápida urbanización e incrementar la sostenibilidad del territorio. Así, este modelo, que puede ser replicado en otras regiones, se convierte en una herramienta espacial de apoyo al desarrollo urbano sostenible que ayuda a comprender las complejidades de los asentamientos formales e informales sujetos a diversas estrategias de sostenibilidad.

\section{Referencias bibliográficas}

Aburas, M. M., Ho, Y. M., Ramli, M. F. \& Ash'aari, Z. H. (2016). The simulation and prediction of spatio-temporal urban growth trends using cellular automata models: A review. International Journal of Applied Earth Observation and Geoinformation, 52, 380-389. https://doi.org/10.1016/j.jag.2016.07.007

Aguilera, F. (2006). Predicción del crecimiento urbano mediante sistemas de información geográfica y modelos basados en autómatas celulares. GeoFocus. Revista Internacional de Ciencia y Tecnología de la Información Geográfica, (6), 81-112. http://www.geofocus. org/index.php/geofocus/article/view/90

Aguilera Benavente, F., Gómez Delgado, M. \& Cantergiani, C. C. (2010). Instrumentos de simulación prospectiva del crecimiento urbano. Ciudad y Territorio Estudios Territoriales (cytet), 42(165-6), 481-495. https://recyt.fecyt.es/index.php/CyTET/ article/view/76012 
Amuzurrutia-Valenzuela, D., Aguirre-Salado, C. \& Sánchez-Díaz, G. (2015). ¿Hacia dónde crecerá la ciudad de San Luis Potosí (México) después de 2009? Revista EURE - Revista de Estudios Urbano Regionales, 41(124), 113-137. http://dx.doi.org/10.4067/S025071612015000400006

Banco Interamericano de Desarrollo (BID). (2011). Sostenibilidad urbana en América Latina y el Caribe. https://publications.iadb.org/es/publicacion/16383/sostenibilidad-urbana-enamerica-latina-y-el-caribe

Barredo, J. I., Kasanko, M., McCormick, N. \& Lavalle, C. (2003). Modelling dynamic spatial processes: simulation of urban future scenarios through cellular automata. Landscape and Urban Planning, 64(3), 145-160. https://doi.org/10.1016/S01692046(02)00218-9

Barreira González, P., Aguilera Benavente, F. \& Gómez Delgado, M. (2012). Propuesta de un análisis de sensibilidad para validar modelos prospectivos de simulación de crecimiento urbano basados en autómatas celulares. GeoFocus. Revista Internacional de Ciencia y Tecnología de la Información Geográfica, (12), 303-328. http://www.geofocus.org/ index.php/geofocus/article/view/247

Barreira González, P., Aguilera Benavente, F. \& Gómez Delgado, M. (2015). Propuesta de validación parcial de modelos de simulación de crecimiento urbano basados en autómatas celulares mediante análisis de sensibilidad. Ciencias Espaciales, 8(2), 409430. https://doi.org/10.5377/ce.v8i2.2090

Batty, M. \& Longley, P. A. (1994). Fractal cities: a geometry of form and function. Academic Press.

Batty, M. \& Xie, Y. (1996). Possible cellular automata. En E. Besussi \& A. Cecchini (Eds.), Artificial Worlds and Urban Studies (pp. 191-220). Dipartimento di analisi economica e sociale del territorio (DAEST), Istituto universitario di architettura di Venezia.

Batty, M., Xie, Y. \& Sun, Z. (1999). The dynamics of urban sprawl. Working Paper Series, Paper 15. Centre for Advanced Spatial Analysis, University College London. https:// discovery.ucl.ac.uk/id/eprint/1360/1/paper15.pdf

Bonham-Carter, G. (1994). Geographic Information Systems for Geoscientists. Modelling with GIS. Pergamon. https://doi.org/10.1016/c2013-0-03864-9

Cacciari, M. (2010). La ciudad. Traducido por Moisés Puente. Gustavo Gili.

Champion, T. \& Hugo, G. (2017). New forms of urbanization: Beyond the urban-rural dichotomy. Routledge. https://doi.org/10.4324/9781315248073

Clichevsky, N. (2000). Informalidad y segregación urbana en América Latina. Una aproximación. Serie Medio Ambiente y Desarrollo, 28. Naciones Unidas, Cepal. https://www. cepal.org/es/publicaciones/5712-informalidad-segregacion-urbana-america-latinaaproximacion

Comisión Económica para América Latina y el Caribe (CEPAL). (2002). Las nuevas funciones urbanas: gestión para la ciudad sostenible. Serie Medio Ambiente y Desarrollo, 48. Naciones Unidas, CEPAL. https://www.cepal.org/es/publicaciones/5742-nuevasfunciones-urbanas-gestion-la-ciudad-sostenible

Couclelis, H. (1997). From cellular automata to urban models: new principles for model development and implementation. Environment and Planning B: Planning and Design, 24(2), 165-174. https://doi.org/10.1068/b240165 
Cuervo González, L. M. (2003). Pensar el territorio: los conceptos de ciudad-global y región en sus orígenes y evolución. Serie gestión pública, 40. Instituto Latinoamericano de Planificación Económica y Social (ILPES) - Comisión Económica para América Latina y el Caribe (CEPAL). https://www.cepal.org/es/publicaciones/7293-pensar-territorioconceptos-ciudad-global-region-sus-origenes-evolucion

Durán, G., Martí, M. \& Mérida, J. (2016). Crecimiento, segregación y mecanismos de desplazamiento en el periurbano de Quito. Íconos - Revista de Ciencias Sociales, (56), 123-146. https://doi.org/10.17141/iconos.56.2016.2150

Feng, Y., Liu, Y. \& Batty, M. (2016). Modeling urban growth with GIs based cellular automata and least squares svm rules: a case study in Qingpu-Songjiang area of Shanghai, China. Stochastic Environmental Research and Risk Assessment, 30(5), 1387-1400. https://doi. org/10.1007/s00477-015-1128-z

Feng, Y. \& Tong, X. (2019). Incorporation of spatial heterogeneity-weighted neighborhood into cellular automata for dynamic urban growth simulation. GIscience \& Remote Sensing, 56(7), 1024-1045. https://doi.org/10.1080/15481603.2019.1603187

García de Hernández, N. (2006). La formación de asentamientos informales: un proceso gestado por diferentes actores sociales. Scripta Nova: Revista electrónica de Geografía y Ciencias Sociales, 10(218). http://www.ub.es/geocrit/sn/sn-218-50.htm

García Lamparte, A. M., Santé Riveira, I., Reyes Bueno, F. \& Crecente Maseda, R. (2013). El modelo de autómata celular simula: aplicación para el estudio de patrones de crecimiento urbano sostenible. Revista Geoespacial, (10), 87-101.

Ghosh, P., Mukhopadhyay, A., Chanda, A., Mondal, P., Akhand, A., Mukherjee, S., Nayak, S. K., Ghosh, S., Mitra, D., Ghosh, T. \& Hazra, S. (2017). Application of Cellular automata and Markov-chain model in geospatial environmental modeling - A review. Remote Sensing Applications: Society and Environment, 5, 64-77. https://doi. org/10.1016/j.rsase.2017.01.005

Gómez, D. (2011). Descripción y aplicaciones de los autómatas celulares. http://delta.cs.cinvestav. $\mathrm{mx} /$-mcintosh/cellularautomata/Summer_Research_files/Arti_Ver_Inv_2011_ DARG.pdf

Gómez Salazar, A. \& Cuvi, N. (2016). Asentamientos informales y medio ambiente en Quito. Areas: Revista Internacional de Ciencias Sociales, (35), 101-119. https://revistas.um.es/ areas/article/view/279181

Goodacre, A. K., Bonham-Carter, G. F., Agterberg, F. P. \& Wright, D. F. (1993). A statistical analysis of the spatial association of seismicity with drainage patterns and magnetic anomalies in western Quebec. Tectonophysics, 217(3-4), 285-305. https://doi. org/10.1016/0040-1951(93)90011-8

Hagen-Zanker, A. (2009). An improved Fuzzy Kappa statistic that accounts for spatial autocorrelation. International Journal of Geographical Information Science, 23(1), 6173. https://doi.org/10.1080/13658810802570317

Instituto Nacional de Estadística y Censos (INEC), Ecuador. (2016). Archivo Nacional de Datos y Metadatos Estadísticos (ANDA). https://anda.inec.gob.ec/anda/index.php/catalog

Jackson, K. T. (1985). Crabgrass Frontier: The Suburbanization of the United States. Nueva York, NY: Oxford University Press.

Kennedy, C., Cuddihy, J. \& Engel-Yan, J. (2007). The changing metabolism of cities. Journal of Industrial Ecology, 11(2), 43-59. https://doi.org/10.1162/jie.2007.1107 
Lambin, E. F. (1994). Modelling deforestation processes - A review. Research Report, Joint Research Center, Institute for Remote Sensing Applications; European Space Agency. Office for Official publications of the European Community.

Linares, S. \& Picone, N. (2018). Modelización de la expansión urbana y su impacto en el paisaje natural mediante Sistemas de Información Geográfica y Autómatas Celulares. Caso de estudio: Tandil, Argentina. Revista Estudios Ambientales, 6(1), 5-25. http:// www.fch.unicen.edu.ar/ojs-3.1.0/index.php/estudios-ambientales/article/view/45

Ma, Q. (2020). Integrating ecological correlation into cellular automata for urban growth simulation: A case study of Hangzhou, China. Urban Forestry \& Urban Greening, 51. https://doi.org/10.1016/j.ufug.2020.126697

Maldonado, C. (2014). El (des)orden de las ciudades. Análisis. Revista Colombiana de Humanidades, 46(85), 215-231. https://doi.org/10.15332/s0120-8454.2014.0085.03

Martínez Beltrán, A. G. (2019). Análisis del crecimiento disperso y las relaciones centroperiferia en la ciudad de Quito (1980-2010). III International Seminar on Urban Form - Hispanic (ISUF-H), Guadalajara, México, 18-20 septiembre 2019. https://doi. org/10.4995/isufh2019.2020.10028

Mas, J. F. \& Flamenco, A. (2011). Modelación de los cambios de coberturas/uso del suelo en una región tropical de México. GeoTropico, 5(1), 1-24. http://www.geotropico.org/ NS_5_1_Mas-Flamenco.pdf

Mondal, B., Das, D. N. \& Bhatta, B. (2017). Integrating cellular automata and Markov techniques to generate urban development potential surface: a study on Kolkata agglomeration. Geocarto International, 32(4), 401-419. https://doi.org/10.1080/101 06049.2016 .1155656

Municipio del Distrito Metropolitano de Quito. (2019). Gobierno Abierto. Información Geográfica de descarga. http://gobiernoabierto.quito.gob.ec/?page_id=1122

Muñiz, I., García, M. A. \& Calatayud, D. (2006). sprawl. Definición, causas y efectos. Working Papers (Universitat Autònoma de Barcelona. Departament d'Economia Aplicada). http://hdl.handle.net/2072/3572

ONU-Hábitat (Programa de Naciones Unidas para los Asentamientos Humanos). (2018). Propuesta de Plataforma Urbana y de Ciudades de América Latina y el Caribe. Naciones Unidas, CEPAL. https://www.cepal.org/es/publicaciones/44158-propuesta-plataformaurbana-ciudades-america-latina-caribe

Oyugi, M. O. \& K'Akumu, O. A. (2007). Land use management challenges for the city of Nairobi. Urban Forum, 18, 94-113. https://doi.org/10.1007/BF02681232

Pontius Jr., R. G., Boersma, W., Castella, J.-C., Clarke, K., de Nijs, T., Dietzel, C., Duan, Z., Fotsing, E., Goldstein, N., Kok, K., Koomen, E., Lippitt, C. D., McConnell, W., Mohd Sood, A., Pijanowski, B., Pithadia, S., Sweeney, S., Trung, T. N., Veldkamp, A. T. \& Verburg, P. H. (2008). Comparing the input, output, and validation maps for several models of land change. The Annals of Regional Science, 42, 11-37. https://doi. org/10.1007/s00168-007-0138-2

Rendón-Macías, M. E., Riojas-Garza, A., Contreras-Estrada, D. \& Martínez-Ezquerro, J. D. (2018). Análisis bayesiano. Conceptos básicos y prácticos para su interpretación y uso. Revista Alergia México, 65(3), 285-298. https://doi.org/10.29262/ram.v65i3.512 
Rodrigues, H. O., Soares-Filho, B. S. \& Costa, W. L. D. S. (2007). Dinamica Ego, uma plataforma para modelagem de sistemas ambientais. Anais XIII Simpósio Brasileiro de Sensoriamento Remoto, Florianópolis, Brasil, 3089-3096.

Rodríguez, M., Grondona-Opazo, G., Erazo, J. \& Festjens, J. (2016). Disputas urbanopopulares: creatividad y antagonismos para la construcción de barrios del Buen Vivir en Quito, Ecuador. En P. Abramo, M. Rodríguez \& J. Erazo (Eds.), Ciudades populares en disputa: ;acceso a suelo urbano para todos? (pp. 33-65). Abya-Yala.

Ruiz-Benito, P., Andivia, E., Archambeaou, J., Astigarraga, J., Barrientos, R., Cruz-Alonso, V., Florencio, M., Gómez, D., Martínez-Baroja, L., Quiles, P., Rohrer, Z., Santos, A. M. C., Velado, E., Villén-Pérez, I. \& Morales-Castilla, I. (2018). Ventajas de la estadística bayesiana frente a la frecuentista: ¿por qué nos resistimos a usarla? Ecosistemas, 27(2), 136-139. https://doi.org/10.7818/ECOS.1591

Sabatini, F. (2003). La segregación social del espacio en las ciudades de América Latina. Documentos del Instituto de Estudios Urbanos, Pontificia Universidad Católica de Chile, Serie Azul, 35, 59-70.

Sahagún-Sánchez, F. J., Reyes-Hernández, H., Flores, J. L. \& Vargas, L. C. (2011). Modelización de escenarios de cambio potencial en la vegetación y el uso de suelo en la Sierra Madre Oriental de San Luis Potosí, México. Journal of Latin American Geography, 10(2), 6586. http://www.jstor.org/stable/23209585

Sakoda, J. M. (1971). The checkerboard model of social interaction. The Journal of Mathematical Sociology, 1(1), 119-132. https://doi.org/10.1080/0022250X.1971.9989791

Scholz, B. I., Rodríguez, J. A. M., Giacometti, J. R. M., Meneses, P. A., Valarezo, A. V. R. \& Cando, P. A. C. (2015). Informe Nacional del Ecuador para la Tercera Conferencia de las Naciones Unidas sobre la Vivienda y el Desarrollo Urbano Sostenible HABITAT III. Ministerio de Desarrollo Urbano y Vivienda del Gobierno de la República del Ecuador (MIDUVI). https://amevirtual.gob.ec/wp-content/uploads/2017/05/Informe-Pais-Ecua dor-Enero-2016_vf.pdf

Soares-Filho, B., Rodrigues, H. \& Costa, W. (2013). Modeling Environmental Dynamics with Dinamica EGO. Guidebook. Britaldo Silveira Soares-Filho. http://csr.ufmg.br/dinamica/ dokuwiki/doku.php?id=tutorial:start

Takeyama, M. (1996). Geocellular: A general platform for dynamic spatial simulation. En E. Besussi \& A. Cecchini (Eds.), Artificial Worlds and Urban Studies (pp. 347-364). Dipartimento di analisi economica e sociale del territorio (DAEST).

Tobler, W. R. (1970). A computer movie simulating urban growth in the Detroit region. Economic Geography, 46, 234-240. https://doi.org/10.2307/143141

Tobler, W. R. (1995). Migration: Ravenstein, Thornthwaite, and beyond. Urban Geography, 16(4), 327-343. https://doi.org/10.2747/0272-3638.16.4.327

Torrens, P. M. \& Alberti, M. (2000). Measuring sprawl. Working Paper Series, 27. Centre for Advanced Spatial Analysis (UCL). https://discovery.ucl.ac.uk/id/eprint/1370

Ulloa, R. \& Lalama, E. (2018). Geopronósticos de asentamientos con construcciones civiles en las periferias de la ciudad basado en autómatas celulares: caso zona norte-calderón. Revista Geoespacial, 15(1), 45-59. http://dx.doi.org/10.24133/geoespacial.v15i1.1262

United Nations. (2019). World Urbanization Prospects. The 2018 Revision. https://population. un.org/wup/Publications/Files/WUP2018-Report.pdf 
Vaggione, P. (2014). Planeamiento urbano para autoridades locales. ONU Hábitat. https:// unhabitat.org/planeamiento-urbano-para-autoridades-locales

Valenzuela Montes, L. M., Aguilera Benavente, F., Soria Lara, J. A. \& Molero Melgarejo, E. (2008). Creation and evaluation of development scenarios for metropolitan patterns. En M. Paegelow \& M. T. C. Olmedo (Eds.), Modelling Environmental Dynamics. Environmental Science and Engineering (Environmental Science) (pp. 339-362). Springer. https://doi.org/10.1007/978-3-540-68498-5_13

Weisstein, E. W. (2019). Elementary Cellular Automaton. MathWorld - A Wolfram Web Resource. https://mathworld.wolfram.com/ElementaryCellularAutomaton.html

White, R. \& Engelen, G. (1993). Cellular Automata and Fractal Urban Form: A cellular modelling approach to the evolution of urban land-use patterns. Environment and Planning A: Economy and Space, 25(8), 1175-1199. https://doi.org/10.1068/a251175

White, R. \& Engelen, G. (1997). Cellular automata as the basis of integrated dynamic regional modelling. Environment and Planning B: Planning and Design, 24(2), 235-246. https://doi.org/10.1068/b240235

White, R. \& Engelen, G. (2000). High-resolution integrated modelling of the spatial dynamics of urban and regional systems. Computers, Environment and Urban Systems, 24(5), 383-400. https://doi.org/10.1016/S0198-9715(00)00012-0

Zhang, Y., Yang, Z. \& Yu, X. (2009). Ecological network and energy analysis of urban metabolic systems: Model development, and a case study of four Chinese cities. Ecological Modelling, 220(11), 1431-1442. https://doi.org/10.1016/j.ecolmodel.2009.02.001 